\title{
Integrated Inventory Model for Deteriorating Items with Price-Dependent Demand under Quantity-Dependent Trade Credit
}

\author{
Karuppuchamy Annadurai \\ Department of Mathematics, Government Arts College, Udumalpet, Tirupur District, Tamil Nadu 642126, India \\ Correspondence should be addressed to Karuppuchamy Annadurai; anna.vadivu@gmail.com
}

Received 12 March 2013; Accepted 1 October 2013

Academic Editors: A. Che and G. Onwubolu

Copyright (C) 2013 Karuppuchamy Annadurai. This is an open access article distributed under the Creative Commons Attribution License, which permits unrestricted use, distribution, and reproduction in any medium, provided the original work is properly cited.

\begin{abstract}
This paper explores an integrated inventory model when the deterioration rate follows exponential distribution under trade credit. Here, it is assumed that demand rate is a function of selling price and the permissible delay in payment depends on the order quantity. In the model shortages are completely backlogged. The maximization of the total profit per unit of time is taken as the objective function to study the retailer's optimal ordering policy. This paper also presents a practical application example where the proposed inventory model is utilized to support business decision making. Particularly, the model developed in the paper could be useful in the area of supply chain management. Finally, sensitivity analysis of the optimal solution with respect to major parameters is carried out. Our result illustrates that this model can be quite useful in determining the optimal ordering policy when the trade credit period is being analyzed.
\end{abstract}

\section{Introduction}

Both in deterministic and probabilistic inventory models of classical type, it is observed that payments are made to the supplier immediately after receiving the items. In practice, the supplier will offer the retailer a delay period in payment for the amount of purchase to increase the demand known as trade credit period. Offering such a credit period to the retailer will encourage the supplier's selling and reduce onhand stock level. Simultaneously, without a primary payment the retailer can take the advantages of a credit period to reduce cost and increase profit. The customer does not have to pay any interest during the fixed period but if the payment gets delayed beyond the period interest will be charged by the supplier. This arrangement comes out to be very advantageous to the customer as he may delay the payment till the end of the permissible delay period. During this credit period the retailer can start to accumulate revenues on the sales and earn interest on that revenue. Thus, the delay in the payment offered by the supplier is a kind of price discount since paying later indirectly reduces the cost of holding and it encourages the retailers to increase their order quantity. Moreover, paying later indirectly reduces the cost of holding stock. Hence, trade credit can play an important role in inventory model for both the suppliers as well as the retailers in integrated inventory model. Goyal [1] first derived an EOQ model under the conditions of permissible delay in payments. Chung and Huang [2] extended Goyal's [1] model to consider the case that the units are replenished at a finite rate under permissible delay in payments. Teng [3] assumed that selling price is not equal to the purchasing price to modify Goyal's model [1]. Salameh et al. [4] extended this issue to the continuous review inventory model.

The control and maintenance of inventories for deteriorating items with shortages have received much attention of several researchers in the recent years because most of the physical goods are deteriorated over time. Deterioration refers to decay, damage, or spoilage. In respect of foods, films, drugs, chemicals, electronic components, and radioactive substances, deterioration may happen during normal period of storage. Therefore, the loss due to deterioration can not be neglected. So, decay or deterioration of physical goods 
in stock is a very realistic feature and researchers felt the necessity to take this factor into consideration in developing inventory models. Goyal and Giri [5] studied recent trends in modeling of deteriorating inventory. Various types of inventory models with constant deterioration rate and a linearly time varying demand rate were discussed by Goswami and Chaudhuri [6], Chakrabarti and Chaudhuri [7], Giri et al. [8], and others. Jalan and Chaudhuri [9] discussed inventory models with constant demand, constant deterioration, and instantaneous replenishment. Inventory models with a fixed deteriorating rate and an exponentially time varying demand were studied by Hariga and Benkherouf [10], Wee [11], and others. Jamal et al. [12] and Chang and Dye [13] extended Goyal's [1] model to the case for deterioration and allowable shortages. Annadurai and Uthayakumar [14] analyzed the partial trade credit financing in a supply chain by EOQbased model for decaying items by allowing shortages. They assumed that the supplier may offer a partial permissible delay in payments even if the order quantity is less than predetermined quantity. From the sensitivity analysis, it was proved that the deterioration rate, ordering cost, and purchasing cost affect the total profit of the retailer. Recently, Annadurai [15] developed a mathematical model for obtaining the optimal purchase quantity for exponentially distributed deteriorating items with some salvage value associated with the deteriorated items and partial backlogging.

At the beginning, demand rate was assumed to be constant which is in general likely to be time dependent and stock dependent. Burwell et al. [16] developed economic lot size model for price-dependent demand under quantity and freight discounts. Inventory model for ameliorating items for price-dependent demand rate was proposed by Mondal et al. [17] and inventory model with price- and time-dependent demand was developed by You [18]. Wee [19] developed a replenishment policy for items with a price-dependent demand and varying rate of deterioration. Lin et al. [20] developed an economic order quantity model with time varying demand, partial back ordering, and linearly timedependent deterioration rate. Annadurai and Uthayakumar [21] developed an inventory model under two levels of trade credit policy for deteriorating items by assuming that the demand is a function of credit period offered by the retailer to the customers. In a recent paper, Annadurai [22] presented an integrated inventory model for exponentially deteriorated items with back orders under two levels of trade credit. He considered the impact of a replenishment policy on the timing of the cash flows associated with payments to suppliers and revenue streams from customers. That is, the same cash amount will possess different money value at different future time.

There are some other research articles dealing with deteriorating inventory model under trade credit. Aggarwal and Jaggi [23] developed ordering policies of deteriorating items under permissible delay in payments. Chang et al. [24] established an inventory model for deteriorating items with linear trend demand under conditions of permissible delay in payments. Dye [25] proposed inventory model by considering the stock-dependent demand for deteriorating items for partial backlogging and conditions of permissible delay in payments. He used initial stock-dependent demand function. In the existing literature about permissible delay in payments, it is assumed that the demand is either mostly a function of time or a function of the retail price. Soni and Shah [26] established optimal ordering policy for stockdependent demand under progressive payment scheme. In a recent paper, Tripathy and Mishra [27] dealt with development of an inventory model when the deterioration rate follows Weibull two-parameter distributions. It was assumed that demand rate is a function of selling price and holding cost is time dependent. From their model, one can calculate the optimum average profit margins for with shortage case and without shortage case for the deterministic inventory model with varying demand rate and holding cost subject to the conditions. In a recent paper, Annadurai and Uthayakumar [28] formulated a two-echelon inventory model for deteriorating items with credit-period-dependent demand including shortages under two-level trade credit financing and determining the retailer's optimal replenishment policy when both the supplier as well as the retailer offers the credit period to stimulate customer demand.

In real life, the occurrence of shortage in an inventory system is a phenomenon. Shortages are of great importance especially in a model that considers a delay in payment due to the fact that shortages can affect the quantity ordered to benefit from the delay in payment. Now there arises a natural question whether the length of the permissible delay period gets influenced by the volume of the quantity ordered. Intuition leads to the fact that the volume of the ordered quantity should have a direct impact on the length of this period. More precisely, we can say that the more we order the longer the delay period is likely to be allotted.

The present paper incorporates this fact in an integrated inventory model allowing for shortages and obtains the optimal replenishment policy for deteriorating items with price-dependent demand under quantity-dependent trade credit. That is, if the order quantity is less than the predetermined quantity, the payment for the items must be made immediately. Otherwise, a fixed trade credit period is permitted. Next, we provide the fundamental notations and assumptions for the proposed model in Section 2. In Section 3, a mathematical model is established and solution procedure is discussed for maximizing the total profit, based on which an algorithm for finding the optimal policy is suggested. Numerical examples are provided to illustrate the proposed model in Section 4. In Section 5, sensitivity analysis of the optimal solution with respect to major parameters is carried out. Lastly, in Section 6, we draw the conclusions and give suggestions for future research.

\section{Notations and Assumptions}

The proposed model is developed based on the following assumptions and notations.

2.1. Notations. The notation is summarized in the following:

A: ordering cost per order,

Q: ordering quantity, 
$Q_{0}$ : a specified value of $Q$,

$T$ : the inventory cycle length of each cycle,

$t_{1}$ : time when the inventory level comes down to zero,

$\theta$ : the deterioration rate, where $0 \leq \theta<1$,

$C$ : unit purchase cost of the item,

$C_{1}$ : shortage cost for backlogged item,

$p$ : selling price per unit item,

$M$ : permissible delay period in settling the accounts, $0 \leq M \leq T$,

$h$ : the inventory holding rate per unit time excluding interest charges,

$I_{e}$ : interest which can be earned per $\$$ per unit time,

$I_{k}$ : interest payable per $\$$ per unit time,

$I(t)$ : the inventory level at time $t$,

TP: the total profit per unit time.

2.2. Assumptions. The following assumptions are made in the model.

(1) Replenishment occurs instantaneously at an infinite rate. That is, lead time is zero.

(2) The demand rate is a function of selling price.

(3) Shortages are allowed to occur and completely backlogged.

(4) The length of the permissible delay period $M$ for repaying the supplier is given by

$$
M= \begin{cases}M_{1} & \text { if } 0<Q<Q_{0}, \\ M_{2} & \text { if } Q \geq Q_{0},\end{cases}
$$

where $Q$ is the ordered quantity, $Q_{0}$ is a specified value of $Q$, and $M_{2}>M_{1}$.

(5) No payment to the supplier is outstanding at the time of placing an order; that is, $M<T$.

(6) The retailer can accumulate revenue and earn interest from the very beginning that his customer pays for the amount of purchasing cost to the retailer until the end of the trade credit period offered by the supplier. That is, the retailer can accumulate revenue and earn interest during the period $t=M$ with rate $I_{e}$ under the condition of trade credit.

(7) There is no repair or replacement of deteriorated units during the planning horizon. The item will be withdrawn from warehouse immediately as they become deteriorated.

(8) The inventory carrying cost is proportional to the inventory level and the deterioration rate is proportional to time.

(9) Selling price $p$ follows an increasing trend, and demand rate possesses the negative derivative throughout its domain where demand rate is $f(p)=(a-p)>0$.

\section{Mathematical Formulation and Solution}

In this section, a mathematical model is developed to determine the optimal replenishment cycle time that maximizes the total annual profit in an inventory system for exponential deteriorating items under quantity-dependent permissible delay in payments including shortages. Let $I(t)$ be the inventory level at time $0 \leq t \leq T$. Inventory level decreases due to both the demand and deterioration of the item during the period $\left[0, t_{1}\right]$ and ultimately falls to zero at $t=t_{1}$. Thereafter, shortages are allowed to occur and all of the demands during the period $\left[t_{1}, T\right]$ are completely backlogged.

As described above, the differential equation representing the inventory status is given by

$$
\frac{d I(t)}{d t}= \begin{cases}-(a-p)-\theta I(t) & \text { if } 0 \leq t \leq t_{1} \\ -(a-p) & \text { if } t_{1} \leq t \leq T\end{cases}
$$

with boundary condition $I(t)=0$ at $t=t_{1}$. The solution of (2) is given by

$$
I(t)= \begin{cases}\frac{(a-p)}{\theta}\left[e^{\theta\left(t_{1}-t\right)}-1\right] & \text { if } 0 \leq t \leq t_{1}, \\ (a-p)\left(t-t_{1}\right) & \text { if } t_{1} \leq t \leq T .\end{cases}
$$

The beginning inventory level for each cycle can be obtained as

$$
S=I(0)=\frac{(a-p)}{\theta}\left(e^{\theta t_{1}}-1\right)
$$

The total number of items that become deteriorated in the interval $\left[0, t_{1}\right]$, say $D_{\tau}$, is given by

$$
D_{\tau}=S-\int_{0}^{t_{1}}(a-p) d t=\frac{(a-p)}{\theta}\left(e^{\theta t_{1}}-\theta t_{1}-1\right) \text {. }
$$

Hence, the order quantity per cycle is given by

$$
\begin{aligned}
Q & =D_{\tau}+\int_{0}^{T}(a-p) d t \\
& =\frac{(a-p)}{\theta}\left(e^{\theta t_{1}}-\theta t_{1}-1\right)+(a-p) T .
\end{aligned}
$$

Next, the total profit per unit of time of the inventory system is computed using the following various components.

(1) Ordering cost $=A$.

(2) Holding cost (excluding interest charges) per cycle $=$ $h \int_{0}^{t_{1}} I(t) d t=\left(h(a-p) / \theta^{2}\right)\left(e^{\theta t_{1}}-\theta t_{1}-1\right)$.

(3) Purchase cost $=\mathrm{CQ}=(C(a-p) / \theta)\left(e^{\theta t_{1}}-\theta t_{1}-1\right)+$ $C(a-p) T$.

(4) Shortage cost $=C_{1} \int_{t_{1}}^{T} I(t) d t=\left(C_{1} / 2\right)(a-p)\left(T-t_{1}\right)^{2}$.

There are two major cases to occur in the interest charged and earned in each order cycle and we discuss each case in detail as follows. 
Case $1\left(M \leq t_{1}\right)$. In this case, since the length of period with positive stock is larger than the credit period, the buyer can use the revenue to earn interest at the rate $I_{e}$ per dollar per year in $\left(0, t_{1}\right)$. Hence, the interest earned per unit time is calculated and is given by $I_{e} p \int_{0}^{t_{1}}-(a-p)\left(t-t_{1}\right) d t=$ $I_{e} p(a-p)\left(t_{1}^{2} / 2\right)$. On the other hand, beyond the credit period, the unsold stock is supposed to be financed with rate $I_{k}$ and the interest payable in each order cycle is given by $I_{k} C \int_{M}^{t_{1}}(a-p)\left(t_{1}-t\right) d t=\left(I_{k} C(a-p) / 2\right)\left(t_{1}-M\right)^{2}$.

Hence, the total profit per unit time is given by

$$
\begin{aligned}
& \mathrm{TP}_{1}\left(t_{1}, T, p\right) \\
& =p(a-p)-\frac{a-p}{T} \\
& \quad \times\left\{\frac{A}{a-p}+\frac{(h+C \theta)}{\theta^{2}}\left(e^{\theta t_{1}}-\theta t_{1}-1\right)+C T\right. \\
& \left.\quad+\frac{1}{2}\left[C_{1}\left(T-t_{1}\right)^{2}+I_{k} C\left(t_{1}-M\right)^{2}-I_{e} p t_{1}^{2}\right]\right\} .
\end{aligned}
$$

Let $t_{1}=\gamma T, 0<\gamma<1$. Hence, we get the profit function

$$
\begin{aligned}
& \mathrm{TP}_{1}(T, p) \\
& =p(a-p)-\frac{a-p}{T} \\
& \quad \times\left\{\frac{A}{a-p}+\frac{(h+C \theta)}{\theta^{2}}\left(e^{\theta \gamma T}-\theta \gamma T-1\right)+C T\right. \\
& \quad+\frac{1}{2}\left[C_{1}(1-\gamma)^{2}-\left(I_{e} p-I_{k} C\right) \gamma^{2}\right] T^{2} \\
& \left.\quad+\frac{I_{k} C}{2} M(M-2 \gamma T)\right\} .
\end{aligned}
$$

Our objective is to maximize the profit function $\mathrm{TP}_{1}(T, p)$. The necessary conditions for maximizing the profit are $\partial \mathrm{TP}_{1}(T, p) / \partial T=0$ and $\partial \mathrm{TP}_{1}(T, p) / \partial p=0$ which yield

$$
\begin{aligned}
& \frac{\partial \mathrm{TP}_{1}(T, p)}{\partial T} \\
& =\frac{a-p}{T^{2}}\left\{\frac{A}{a-p}+\frac{(h+C \theta)}{\theta^{2}}\left(e^{\theta \gamma T}-\theta \gamma T-1\right)+C T\right. \\
& +\frac{1}{2}\left[C_{1}(1-\gamma)^{2}-\left(I_{e} p-I_{k} C\right) \gamma^{2}\right] T^{2} \\
& \left.+\frac{I_{k} C}{2} M(M-2 \gamma T)\right\} \\
& -\frac{a-p}{T}\left[\frac{(h+C \theta)}{\theta} \gamma\left(e^{\theta \gamma T}-1\right)\right. \\
& +\left[C_{1}(1-\gamma)^{2}-\left(I_{e} p-I_{k} C\right) \gamma^{2}\right] T \\
& \left.+C-I_{k} C M \gamma\right]=0
\end{aligned}
$$

$$
\begin{aligned}
& \frac{\partial \mathrm{TP}_{1}(T, p)}{\partial p} \\
& =a-2 p \\
& \quad+\frac{1}{T}\left\{\frac{(h+C \theta)}{\theta^{2}}\left(e^{\theta \gamma T}-\theta \gamma T-1\right)-C T\right. \\
& \quad-\frac{1}{2}\left[C_{1}(1-\gamma)^{2}-\left(I_{e} p-I_{k} C\right) \gamma^{2}\right] T^{2} \\
& \left.\quad-\frac{I_{k} C}{2} M(M-2 \gamma T)\right\}=0 .
\end{aligned}
$$

Using the software MATLab 7.0, from (9), we can calculate the optimum values of $T^{*}$ and $p^{*}$ simultaneously. From (9), the optimal value $\operatorname{TP}_{1}^{*}(T, p)$ of the average net profit can be determined provided $T^{*}$ and $p^{*}$ satisfy the conditions $\partial^{2} \mathrm{TP}_{1}(T, p) / \partial T^{2}<0, \partial^{2} \mathrm{TP}_{1}(T, p) / \partial p^{2}<0$ and $\left(\partial^{2} \mathrm{TP}_{1}(T, p) / \partial T^{2}\right)\left(\partial^{2} \mathrm{TP}_{1}(T, p) / \partial p^{2}\right)-\left(\partial^{2} \mathrm{TP}_{1}(T, p) /\right.$ $\partial T \partial p)^{2}>0$ at $p=p^{*}$ and $T=T^{*}$.

If the solutions obtained from (9) do not satisfy the sufficiency conditions, then we conclude that no feasible solution will be optimal for the set of parameters taken to solve (9). Such a situation will imply that the parameter values are inconsistent and there are some errors in their estimation.

Case $2\left(M>t_{1}\right)$. In this case, since $M>t_{1}$, the buyer pays no interest but earns interest at the rate $I_{e}$ during the period $[0, M]$. Therefore, the interest earned in this case is calculated and is given by $(a-p) I_{e} P t_{1}\left(M-t_{1} / 2\right)$ and the interest payable in each order cycle $=0$.

Then, in this case, the total profit per unit time is given by

$$
\begin{aligned}
& \mathrm{TP}_{2}\left(t_{1}, T, p\right) \\
& =p(a-p) \\
& \quad-\frac{a-p}{T}\left\{\frac{A}{a-p}+\frac{(h+C \theta)}{\theta^{2}}\left(e^{\theta t_{1}}-\theta t_{1}-1\right)\right. \\
& \left.+C T+\frac{C_{1}}{2}\left(T-t_{1}\right)^{2}-I_{e} p t_{1}\left(M-\frac{t_{1}}{2}\right)\right\} .
\end{aligned}
$$

By letting $t_{1}=\gamma T, 0<\gamma<1$, the profit function becomes

$$
\begin{aligned}
\mathrm{TP}_{2}(T, p) & \\
= & p(a-p)-\frac{a-p}{T} \\
& \times\left\{\frac{A}{a-p}+\frac{(h+C \theta)}{\theta^{2}}\left(e^{\theta \gamma T}-\theta \gamma T-1\right)+C T\right. \\
& \left.+\frac{C_{1}}{2}(1-\gamma)^{2} T^{2}-I_{e} P \gamma T\left(M-\frac{\gamma T}{2}\right)\right\} .
\end{aligned}
$$

Our objective is to maximize the profit function $\mathrm{TP}_{2}(T, p)$. The necessary conditions for maximizing the 
profit are $\partial \mathrm{TP}_{2}(T, p) / \partial T=0$ and $\partial \mathrm{TP}_{2}(T, p) / \partial p=0$ which yield

$$
\begin{aligned}
& \frac{\partial \mathrm{TP}_{2}(T, p)}{\partial T} \\
& =\frac{a-p}{T^{2}}\left\{\frac{A}{a-p}+\frac{(h+C \theta)}{\theta^{2}}\left(e^{\theta \gamma T}-\theta \gamma T-1\right)+C T\right. \\
& \left.+\frac{C_{1}}{2}(1-\gamma)^{2} T^{2}-I_{e} p \gamma T\left(M-\frac{\gamma T}{2}\right)\right\} \\
& -\frac{a-p}{T}\left[\frac{(h+C \theta)}{\theta} \gamma\left(e^{\theta \gamma T}-1\right)+C_{1}(1-\gamma)^{2} T\right. \\
& \left.+C+I_{e} p \gamma(\gamma T-M)\right]=0, \\
& \frac{\partial \mathrm{TP}_{2}(T, p)}{\partial p} \\
& =a-2 p+\frac{1}{T} \\
& \times\left\{\frac{(h+C \theta)}{\theta^{2}}\left(e^{\theta \gamma T}-\theta \gamma T-1\right)+C T\right. \\
& \left.+\frac{C_{1}}{2}(1-\gamma)^{2}-I_{e} p \gamma T\left(M-\frac{\gamma T}{2}\right)\right\}=0 .
\end{aligned}
$$

Using the software MATLab 7.0, from (12), we can calculate the optimum values of $T^{*}$ and $p^{*}$ simultaneously. From (11), the optimal value $\operatorname{TP}_{2}^{*}(T, p)$ of the average net profit can be determined provided $T^{*}$ and $p^{*}$ satisfy the sufficient conditions $\partial^{2} \mathrm{TP}_{2}(T, p) / \partial T^{2}<0, \partial^{2} \mathrm{TP}_{2}(T, p) / \partial p^{2}<$ 0 and $\left(\partial^{2} \mathrm{TP}_{2}(T, p) / \partial T^{2}\right)\left(\partial^{2} \mathrm{TP}_{2}(T, p) / \partial p^{2}\right)-\left(\partial^{2} \mathrm{TP}_{2}(T, p) /\right.$ $\partial T \partial p)^{2}>0$ at $p=p^{*}$ and $T=T^{*}$.

If the solutions obtained from (12) do not satisfy the sufficiency conditions, then we conclude that no feasible solution will be optimal for the set of parameters taken to solve (12). Such a situation will imply that the parameter values are inconsistent and there are some errors in their estimation.

We observe the following property of optimal $t_{1}, T$, and $p$.

Result 1. $\mathrm{TP}^{M}\left(t_{1}, T, p\right)$ is an increasing function of $M$.

Proof. We observe that for given $\left(t_{1}, T, p\right), \mathrm{TP}_{1}^{M}\left(t_{1}, T, p\right)$ and $\operatorname{TP}_{2}^{M}\left(t_{1}, T, p\right)$ are increasing functions of $M$. Now, consider any $M_{1}$ and $M_{2}$ such that $M_{2}>M_{1}$.

(i) Suppose $M_{1}<M_{2}<t_{1}$. Then, $\operatorname{TP}^{M_{1}}\left(t_{1}, T, p\right)=$ $\mathrm{TP}_{1}^{M_{1}}\left(t_{1}, T, p\right)>\mathrm{TP}_{1}^{M_{2}}\left(t_{1}, T, p\right)=\mathrm{TP}^{M_{2}}\left(t_{1}, T, p\right)$.

(ii) Suppose $M_{1}<t_{1}<M_{2}$. Then, $\mathrm{TP}^{M_{1}}\left(t_{1}, T, p\right)=$ $\mathrm{TP}_{1}^{M_{1}}\left(t_{1}, T, p\right)>\mathrm{TP}_{1}^{M_{2}}\left(t_{1}, T, p\right)>\mathrm{TP}_{2}^{M_{2}}\left(t_{1}, T, p\right)=$ $\mathrm{TP}^{M_{2}}\left(t_{1}, T, p\right)$.

(iii) Suppose $t_{1}<M_{1}<M_{2}$. Then, $\mathrm{TP}^{M_{1}}\left(t_{1}, T, p\right)=$ $\mathrm{TP}_{2}^{M_{1}}\left(t_{1}, T, p\right)>\mathrm{TP}_{2}^{M_{2}}\left(t_{1}, T, p\right)=\mathrm{TP}^{M_{2}}\left(t_{1}, T, p\right)$.

Hence, the result follows.
TABLE 1: Optimal solutions under different parametric values of Example 1.

\begin{tabular}{lccccc}
\hline$\theta$ & $t_{1}^{*}$ & $T^{*}$ & $Q^{*}$ & $p^{*}$ & $\mathrm{TP}\left(t_{1}^{*}, T^{*}, p^{*}\right)$ \\
\hline 0.03 & 0.041 & 0.082 & 161.568 & 28.157 & 1284.232 \\
0.06 & 0.042 & 0.085 & 160.356 & 29.348 & 1281.513 \\
0.09 & 0.044 & 0.089 & 159.314 & 30.523 & 1279.354 \\
\hline
\end{tabular}

TABLE 2: Optimal solutions under different parametric values of Example 2.

\begin{tabular}{lccccc}
\hline$\theta$ & $t_{1}^{*}$ & $T^{*}$ & $Q^{*}$ & $p^{*}$ & $\mathrm{TP}\left(t_{1}^{*}, T^{*}, p^{*}\right)$ \\
\hline 0.03 & 0.054 & 0.109 & 162.382 & 30.451 & 1286.364 \\
0.06 & 0.056 & 0.112 & 161.351 & 31.343 & 1285.348 \\
0.09 & 0.058 & 0.115 & 160.131 & 32.013 & 1283.814 \\
\hline
\end{tabular}

Based on the above result, we develop the following algorithm to find the optimal values of $T$ and $p$ and then, after knowing optimal $T$ and $p$, we can determine the optimal $t_{1}$.

Algorithm

Step 1. Find $\left(T^{*}, p^{*}\right)$ maximizing $\mathrm{TP}^{M_{2}}(T, p)$.

Step 2. If $(a-p) T^{*} \geq Q_{0}$, then $\left(T^{*}, p^{*}\right)$ is optimal. Otherwise, go to Step 3.

Step 3. Find $\left(T^{* *}, p^{* *}\right)$ maximizing $\mathrm{TP}^{M_{1}}(T, p)$.

Step 4. Compute $\mathrm{TP}^{M_{1}}\left(T^{* *}, p^{* *}\right)$ and $\mathrm{TP}^{M_{2}}\left(T^{0}, p^{0}\right)$, where $(a-p) T^{0}=Q_{0}$ and $T^{0}$ is the optimal value of $T$ for given $T=T^{0}$.

Step 5. If $\mathrm{TP}^{M_{1}}\left(T^{* *}, p^{* *}\right) \geq \mathrm{TP}^{M_{2}}\left(T^{0}, p^{0}\right)$, then $\left(T^{* *}, p^{* *}\right)$ is optimal; otherwise, $\left(T^{0}, p^{0}\right)$ is optimal.

Once we have optimal solution $\left(T^{*}, p^{*}\right)$, then we can find the optimal $t_{1}^{*}=\gamma T^{*}$.

\section{Numerical Examples}

4.1. Example 1. In order to evaluate the proposed model in the presented paper, we designed numerical example for different values of $\theta: A=\$ 250$ per order, $a=100, h=\$ 1.5$ per unit per year, $C=\$ 15$ per unit, $C_{1}=\$ 1.5$ per unit per year, $I_{k}=0.1$ and $I_{e}=0.2, \gamma=0.5$, and

$$
M= \begin{cases}M_{1} & \text { if } 0<Q<Q_{0}, \\ M_{2} & \text { if } Q \geq Q_{0},\end{cases}
$$

where $M_{1}=0.055$ year, $M_{2}=0.082$ year, and $Q_{0}=15000$.

With the help of the software MATLab 7.0 we apply the proposed algorithm to solve the problem for the values $\theta=$ $0.03,0.06$, and 0.09 . The results are summarized in Table 1. 
TABLE 3: Effect of change in various parameters of Example 1.

\begin{tabular}{|c|c|c|c|c|c|c|}
\hline \multirow{2}{*}{ Changing parameter } & \multirow{2}{*}{$\%$ Change in system } & \multicolumn{5}{|c|}{ Change in } \\
\hline & & $t_{1}^{*}$ & $T^{*}$ & $Q^{*}$ & $p^{*}$ & $\mathrm{TP}\left(t_{1}^{*}, T^{*}, p^{*}\right)$ \\
\hline \multirow{4}{*}{$h$} & -50 & 0.029 & 0.052 & 155.312 & 31.536 & 1288.642 \\
\hline & -25 & 0.038 & 0.061 & 157.583 & 30.324 & 1281.521 \\
\hline & +25 & 0.042 & 0.083 & 168.358 & 29.467 & 1280.323 \\
\hline & +50 & 0.044 & 0.084 & 174.347 & 27.358 & 1272.514 \\
\hline \multirow{4}{*}{$a$} & -50 & 0.044 & 0.085 & 158.357 & 24.325 & 1202.512 \\
\hline & -25 & 0.041 & 0.082 & 162.356 & 27.524 & 1231.321 \\
\hline & +25 & 0.024 & 0.061 & 171.581 & 28.512 & 1283.245 \\
\hline & +50 & 0.016 & 0.053 & 173.384 & 29.518 & 1292.511 \\
\hline \multirow{4}{*}{$C_{1}$} & -50 & 0.051 & 0.089 & 163.348 & 26.523 & 1271.412 \\
\hline & -25 & 0.048 & 0.082 & 162.365 & 27.341 & 1275.241 \\
\hline & +25 & 0.031 & 0.053 & 155.381 & 31.621 & 1282.523 \\
\hline & +50 & 0.027 & 0.042 & 155.219 & 36.325 & 1291.345 \\
\hline \multirow{4}{*}{$A$} & -50 & 0.039 & 0.080 & 156.581 & 28.025 & 1282.632 \\
\hline & -25 & 0.040 & 0.081 & 158.357 & 27.625 & 1278.782 \\
\hline & +25 & 0.043 & 0.086 & 162.132 & 31.618 & 1280.654 \\
\hline & +50 & 0.045 & 0.088 & 163.245 & 30.812 & 1278.713 \\
\hline \multirow{4}{*}{ C } & -50 & 0.046 & 0.088 & 163.413 & 26.514 & 1278.612 \\
\hline & -25 & 0.045 & 0.087 & 162.156 & 27.681 & 1279.221 \\
\hline & +25 & 0.039 & 0.082 & 158.913 & 31.625 & 1284.912 \\
\hline & +50 & 0.038 & 0.081 & 157.682 & 32.918 & 1285.613 \\
\hline
\end{tabular}

4.2. Example 2. Given $A=\$ 500$ per order, $a=100, h=\$ 2$ per unit per year, $C=\$ 30$ per unit, $C_{1}=\$ 2.5$ per unit per year, $I_{k}=0.1$ and $I_{e}=0.2, \gamma=0.5$ and

$$
M= \begin{cases}M_{1} & \text { if } 0<Q<Q_{0}, \\ M_{2} & \text { if } Q \geq Q_{0},\end{cases}
$$

where $M_{1}=0.082$ year, $M_{2}=0.019$ year and $Q_{0}=9000$.

With the help of the software MATLab 7.0 and apply the proposed Algorithm to solve the problem for the values $\theta=$ $0.03,0.06$, and 0.09 . The results are summarized in Table 2.

\section{Sensitivity Analysis}

Here we study the effects of changes in the system parameters $h, a, C_{1}, A$, and $C$ on the optimal length of inventory interval with positive inventory $t_{1}^{*}$, the optimal length of order cycle $T^{*}$, the optimal order quantity per cycle $Q^{*}$, the optimal selling price $p^{*}$, and the maximum total profit TP* of Example 1. A sensitivity analysis is performed by changing each of the parameters by $+50 \%,+25 \%,-25 \%$, and $-50 \%$, taking one parameter at a time and keeping the remaining parameters unchanged. The results are shown in Table 3.

Based on the results of Table 3 , we can obtain the following managerial insights.

(1) Increase in the values of the parameter $h$ will result in decrease of $p^{*}$ and $\operatorname{TP}\left(t_{1}^{*}, T^{*}, p^{*}\right)$ but increase of $t_{1}^{*}$, $T^{*}$, and $Q^{*}$.

(2) Decrease in the values of the parameter $h$ will result in increase of $p^{*}$ and $\operatorname{TP}\left(t_{1}^{*}, T^{*}, p^{*}\right)$ but decrease of $t_{1}^{*}$, $T^{*}$, and $Q^{*}$.
(3) Increase in the values of the parameter $a$ will result in increase of $Q^{*}, p^{*}$, and $\operatorname{TP}\left(t_{1}^{*}, T^{*}, p^{*}\right)$ but decrease of $t_{1}^{*}$ and $T^{*}$.

(4) Decrease in the values of the parameter $a$ will result in decrease of $Q^{*}, p^{*}$, and $\operatorname{TP}\left(t_{1}^{*}, T^{*}, p^{*}\right)$ but increase of $t_{1}^{*}$ and $T^{*}$.

(5) Increase in the values of the parameter $C_{1}$ will result in increase of $p^{*}$ and $\operatorname{TP}\left(t_{1}^{*}, T^{*}, p^{*}\right)$ but decrease of $t_{1}^{*}, T^{*}$, and $Q^{*}$.

(6) Decrease in the values of the parameter $C_{1}$ will result in decrease of $p^{*}$ and $\operatorname{TP}\left(t_{1}^{*}, T^{*}, p^{*}\right)$ but increase of $t_{1}^{*}, T^{*}$, and $Q^{*}$.

(7) Increase in the values of the parameter $A$ will result in decrease of $p^{*}$ and $\operatorname{TP}\left(t_{1}^{*}, T^{*}, p^{*}\right)$ but increase of $t_{1}^{*}$, $T^{*}$, and $Q^{*}$.

(8) Decrease in the values of the parameter $A$ will result in increase of $p^{*}$ and $\operatorname{TP}\left(t_{1}^{*}, T^{*}, p^{*}\right)$ but decrease of $t_{1}^{*}, T^{*}$, and $Q^{*}$.

(9) Increase in the values of the parameter $C$ will result in decrease of $t_{1}^{*}, T^{*}$, and $Q^{*}$ but increase of $p^{*}$ and $\mathrm{TP}\left(t_{1}^{*}, T^{*}, p^{*}\right)$.

(10) Decrease in the values of the parameter $C$ will result in increase of $t_{1}^{*}, T^{*}$, and $Q^{*}$ but decrease of $p^{*}$ and $\mathrm{TP}\left(t_{1}^{*}, T^{*}, p^{*}\right)$. 


\section{Concluding Remarks}

In this paper, we formulated an integrated inventory model for deteriorating items where shortage is completely backlogged and the permissible delay in payment depends on the order quantity. The deterministic demand rate is assumed to be a function of selling price. The objective is to determine the retailer's optimal ordering quantity and the optimal length of order cycle for maximizing the profit. An algorithm is suggested to find the optimal ordering policy, which helps the inventory manager to decide whether it would be worthwhile to take advantage of a longer credit period for repaying the supplies by ordering a larger amount of the commodity. Numerical examples are provided to demonstrate the applicability of the proposed models. The sensitivity analysis of the optimal solution with respect to the parameters is also included. The outcome shows that a higher value of deterioration rate causes lower value of order quantity and lower value of inventory cost. Hence, it suggests that the retailer should offer higher credit period to customers as the deterioration rate increases. This implies that credit period offered to customers has positive impact.

This paper also presented a practical application example where the proposed inventory model is utilized to support business decision making. Particularly, the model developed in the paper could be useful in the area of supply chain management. Our result illustrates that this model can be quite useful in determining the optimal ordering policy when the trade credit period is being analyzed. The proposed model can be used in inventory control of certain decaying items such as photographic film, electronic components, and radioactive materials which exhibit stock-dependent consumption.

A natural extension of the model would be to study that the case of $n$ breaks in the permissible delay period. Additionally, this work can be extended for deteriorating items with a two-parameter Weibull distribution. The proposed model can further incorporate more realistic assumptions, such as probabilistic demand and trapezoidal fuzzy deterioration.

\section{Acknowledgments}

The author greatly appreciates the six anonymous reviewers for their very valuable and insightful comments, which helped in improving the paper. The author also wishes to thank the Journal Publishing Editor for her helpful suggestions, which have led to a significant improvement in the earlier version of the paper. Best efforts have been made by the author to revise the paper abiding by the constructive comments of the referees and all their suggestions were incorporated directly into the text.

\section{References}

[1] S. K. Goyal, "Economic order quantity under conditions of permissible delay in payments," Journal of the Operational Research Society, vol. 36, no. 4, pp. 335-338, 1985.

[2] K.-J. Chung and Y.-F. Huang, "The optimal cycle time for EPQ inventory model under permissible delay in payments,"
International Journal of Production Economics, vol. 84, no. 3, pp. 307-318, 2003.

[3] J.-T. Teng, "On the economic order quantity under conditions of permissible delay in payments," Journal of the Operational Research Society, vol. 53, no. 8, pp. 915-918, 2002.

[4] M. K. Salameh, N. E. Abboud, A. N. El-Kassar, and R. E. Ghattas, "Continuous review inventory model with delay in payments," International Journal of Production Economics, vol. 85, no. 1, pp. 91-95, 2003.

[5] S. K. Goyal and B. C. Giri, "Recent trends in modeling of deteriorating inventory," European Journal of Operational Research, vol. 134, no. 1, pp. 1-16, 2001.

[6] A. Goswami and K. Chaudhuri, "EOQ model for an inventory with a linear trend in demand and finite rate of replenishment considering shortages," International Journal of Systems Science, vol. 22, no. 1, pp. 181-187, 1991.

[7] T. Chakrabarti and K. S. Chaudhuri, "An EOQ model for deteriorating items with a linear trend in demand and shortages in all cycles," International Journal of Production Economics, vol. 49, no. 3, pp. 205-213, 1997.

[8] B. C. Giri, T. Chakrabarty, and K. S. Chaudhuri, "A note on a lot sizing heuristic for deteriorating items with time-varying demands and shortages," Computers and Operations Research, vol. 27, no. 6, pp. 495-505, 2000.

[9] A. K. Jalan and K. S. Chaudhuri, "Structural properties of an inventory system with deterioration and trended demand," International Journal of Systems Science, vol. 30, no. 6, pp. 627633, 1999.

[10] M. A. Hariga and L. Benkherouf, "Optimal and heuristic inventory replenishment models for deteriorating items with exponential time-varying demand," European Journal of Operational Research, vol. 79, no. 1, pp. 123-137, 1994.

[11] H. M. Wee, "A deterministic lot-size inventory model for deteriorating items with shortages and a declining market," Computers and Operations Research, vol. 22, no. 3, pp. 345-356, 1995.

[12] A. M. M. Jamal, B. R. Sarker, and S. Wang, "An ordering policy for deteriorating items with allowable shortage and permissible delay in payment," Journal of the Operational Research Society, vol. 48, no. 8, pp. 826-833, 1997.

[13] H.-J. Chang and C.-Y. Dye, "An inventory model for deteriorating items with partial backlogging and permissible delay in payments," International Journal of Systems Science, vol. 32, no. 3, pp. 345-352, 2001.

[14] K. Annadurai and R. Uthayakumar, "Analysis of partial trade credit financing in a supply chain by EOQ-based model for decaying items with shortages," International Journal of Advanced Manufacturing Technology, vol. 61, pp. 1139-1159, 2012.

[15] K. Annadurai, "An optimal replenishment policy for decaying items with shortages and salvage value," International Journal of Management Science and Engineering Management, vol. 8, pp. 38-46, 2013.

[16] T. H. Burwell, D. S. Dave, K. E. Fitzpatrick, and M. R. Roy, "Economic lot size model for price-dependent demand under quantity and freight discounts," International Journal of Production Economics, vol. 48, no. 2, pp. 141-155, 1997.

[17] B. Mondal, A. K. Bhunia, and M. Maiti, "An inventory system of ameliorating items for price dependent demand rate," Computers and Industrial Engineering, vol. 45, no. 3, pp. 443-456, 2003. 
[18] P.-S. You, "Inventory policy for products with price and timedependent demands," Journal of the Operational Research Society, vol. 56, no. 7, pp. 870-873, 2005.

[19] H.-M. Wee, "A replenishment policy for items with a pricedependent demand and a varying rate of deterioration," Production Planning and Control, vol. 8, no. 5, pp. 494-499, 1997.

[20] C. Lin, B. Tan, and W.-C. Lee, "An EOQ model for deteriorating items with time-varying demand and shortages," International Journal of Systems Science, vol. 31, no. 3, pp. 391-400, 2000.

[21] K. Annadurai and R. Uthayakumar, "An inventory model for deteriorating items with credit period dependent demand under two-level trade credit financing," Journal of Advanced Research in Applied Mathematics, vol. 3, pp. 24-46, 2011.

[22] K. Annadurai, "An integrated inventory model for decaying items with time discounting and shortages under two levels of trade credit," Bulletin of Kerala Mathematics Association, vol. 10, pp. 49-66, 2013.

[23] S. P. Aggarwal and C. K. Jaggi, "Ordering policies of deteriorating items under permissible delay in payments," Journal of the Operational Research Society, vol. 46, pp. 658-662, 1995.

[24] H.-J. Chang, C.-H. Hung, and C.-Y. Dye, "An inventory model for deteriorating items with linear trend demand under the condition of permissible delay in payments," Production Planning and Control, vol. 12, no. 3, pp. 274-282, 2001.

[25] C. Y. Dye, "A deteriorating inventory model with stock dependent rate and partial backlogging under conditions of permissible delay in payments," Opsearch, vol. 39, pp. 189-198, 2002.

[26] H. Soni and N. H. Shah, "Optimal ordering policy for stockdependent demand under progressive payment scheme," European Journal of Operational Research, vol. 184, no. 1, pp. 91-100, 2008.

[27] C. K. Tripathy and U. Mishra, "An inventory model for Weibull deteriorating items with price dependent demand and timevarying holding cost," Applied Mathematical Sciences, vol. 4, no. 41-44, pp. 2171-2179, 2010.

[28] K. Annadurai and R. Uthayakumar, "Two-echelon inventory model for deteriorating items with credit period dependent demand including shortages under trade credit," Optimization Letters, vol. 7, pp. 1227-1249, 2013. 

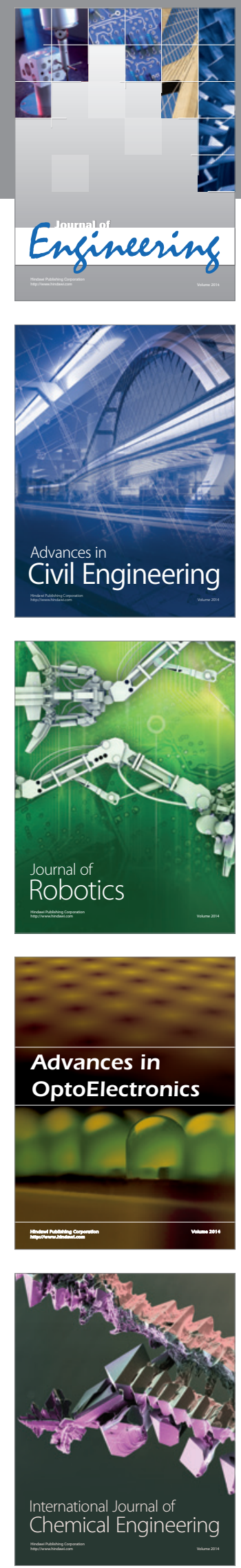

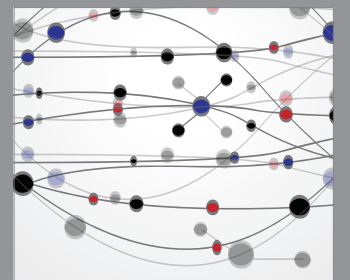

The Scientific World Journal
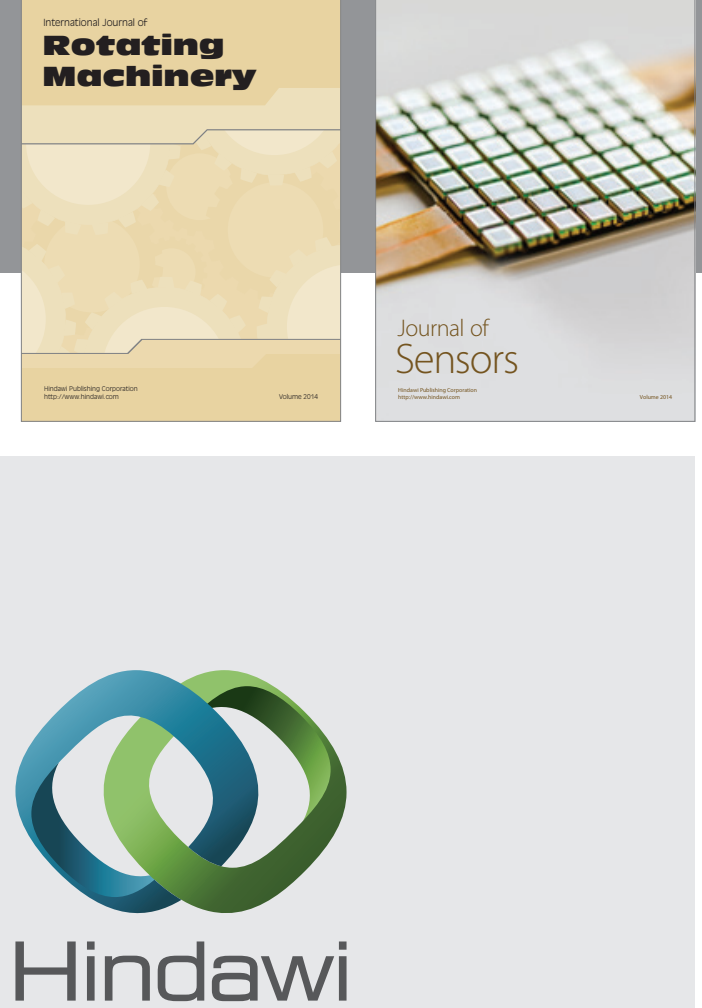

Submit your manuscripts at http://www.hindawi.com
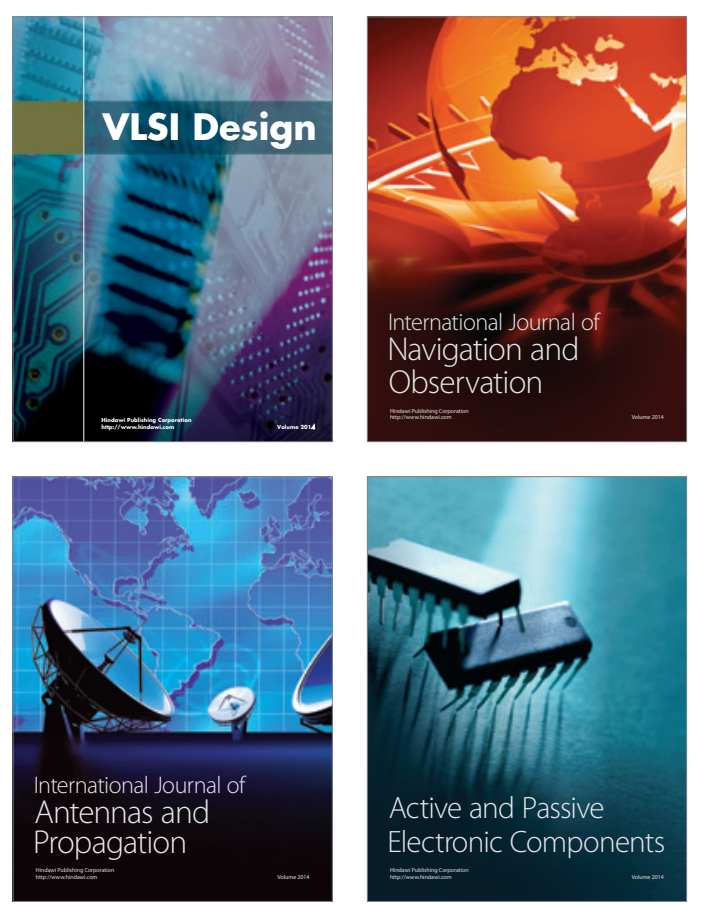
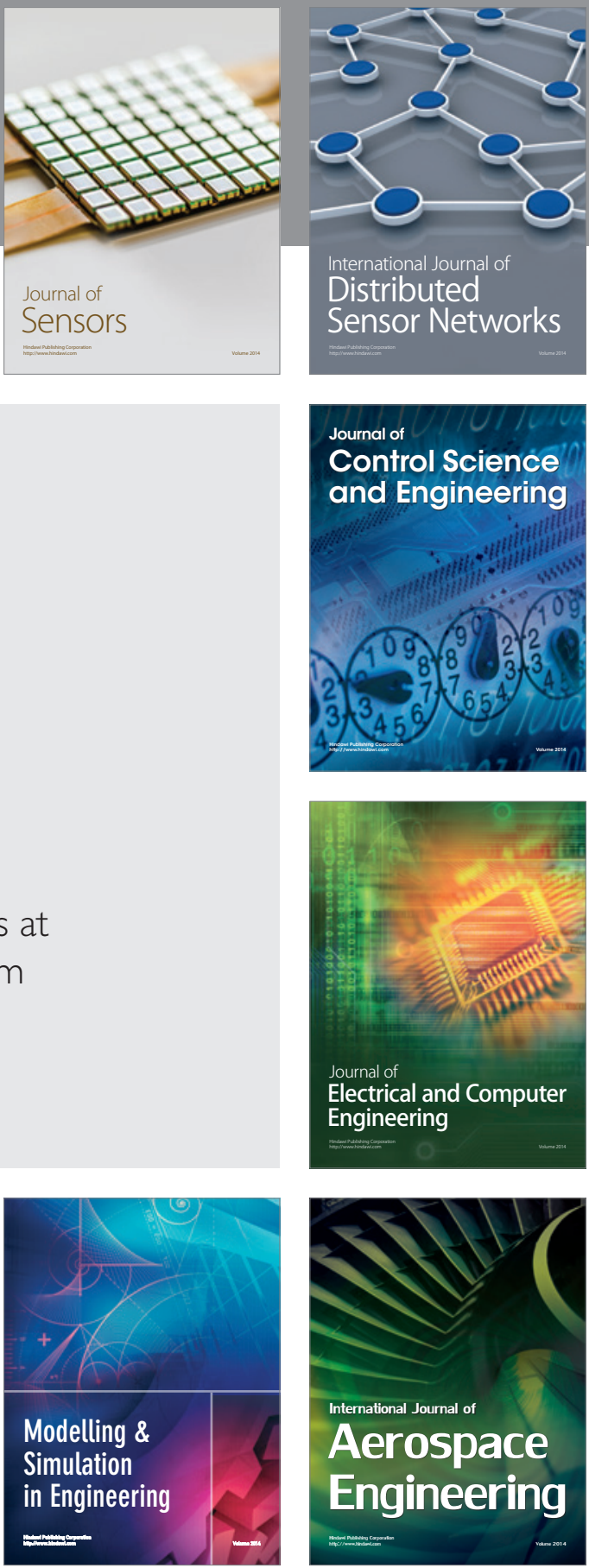

Journal of

Control Science

and Engineering
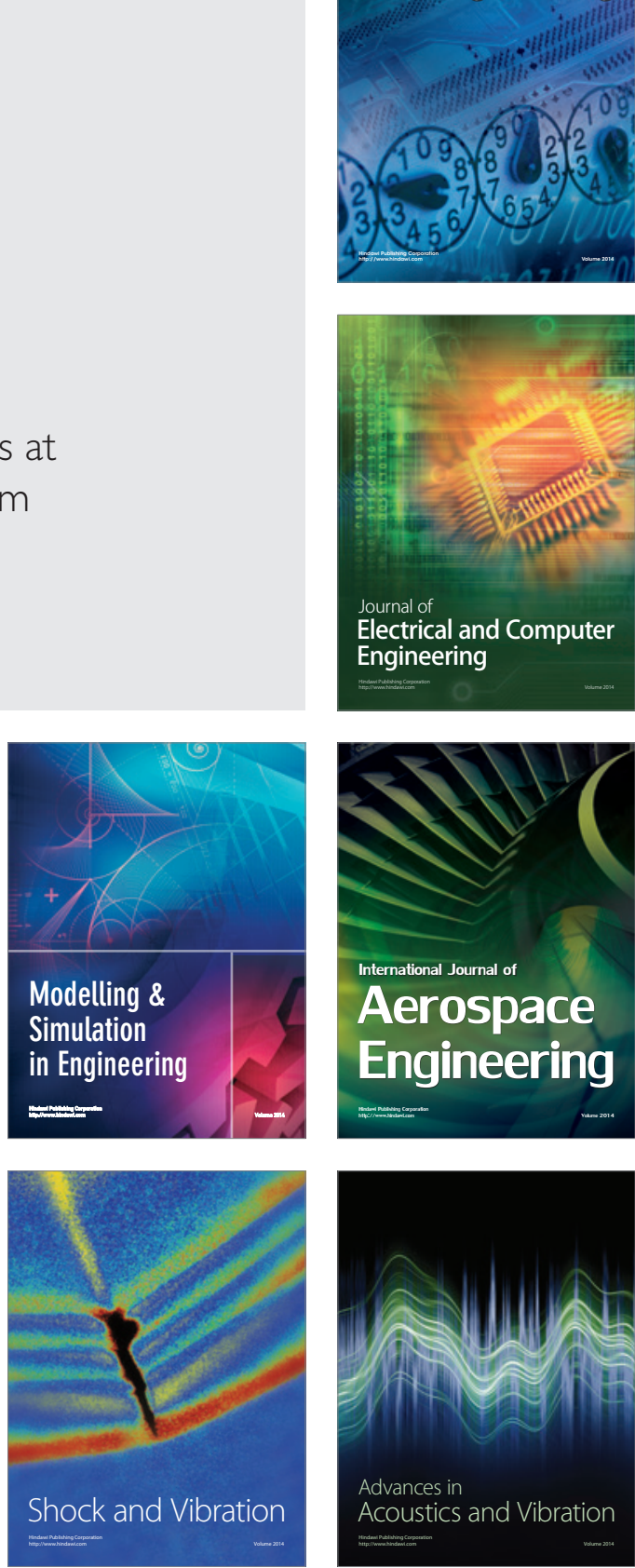